\title{
Hybrid SBR-FO system for wastewater treatment and reuse: Operation, fouling and cleaning
}

\author{
Rodrigo Valladares Linares ${ }^{a}$, Zhenyu Li ${ }^{a, b^{*}}$,Victor Yangali-Quintanilla ${ }^{a, c}$, Qingyu Li $^{a}$, \\ Johannes S. Vrouwenvelder ${ }^{a, d, e}$, Gary L. Amy ${ }^{a}$, Noreddine Ghaffour ${ }^{a, * *}$
}

\begin{abstract}
${ }^{a}$ King Abdullah University of Science and Technology (KAUST), Water Desalination and Reuse Center (WDRC), Biological \& Environmental Science \& Engineering Division (BESE), Thuwal 23955-6900, Saudi

Arabia, Tel. +966128082180, Email: noreddine.ghaffour@kaust.edu.sa

${ }^{b}$ Belfer Center for Science and International Affairs, John F. Kennedy School of Government, Harvard University, Cambridge, MA 02138 United States (USA)

${ }^{c}$ Grundfos Holding A/S, R\&T, Bjerringbro, Denmark

${ }^{d}$ Delft University of Technology, Faculty of Applied Sciences, Department of Biotechnology, Delft, The
\end{abstract} Netherlands

${ }^{e}$ Wetsus, Centre of Excellence for Sustainable Water Technology, Leeuwarden, The Netherlands

\begin{abstract}
Forward osmosis (FO) is a novel membrane separation process that potentially can be used as an energy-saving alternative to conventional membrane processes. A hybrid sequential batch reactor (SBR)-FO process was explored. In this system, a plate and frame FO cell including two flat-sheet FO membranes was submerged in a bioreactor treating synthetic domestic wastewater. The dissolved organic carbon (DOC) removal efficiency of the system was $98.55 \%$. Total nitrogen removal was $62.4 \%$, with nitrate, nitrite and ammonium removals of $58.4 \%, 96.2 \%$ and $88.4 \%$, respectively. Phosphate removal was almost $100 \%$. The 15 -hour cycle average water flux of a virgin membrane with air scouring was $2.95 \mathrm{~L} / \mathrm{m}^{2} . \mathrm{h}$. Air scouring can help to remove loose foulants from the membrane active layer, thus helping to recover up to $89.5 \%$ of the original flux. Chemical cleaning of the fouled active layer of the FO membrane was not as effective as air scouring. Natural organic matter (NOM) characterization methods (liquid chromatography - organic carbon detection (LC-OCD) and 3-D fluorescence excitation emission matrix (FEEM)) show that the FO membrane has a very good performance in rejecting biopolymers, humics and building blocks, but a limited ability in rejecting low molecular weight neutrals. Transparent exopolymer particles (TEP) and other biopolymers might be associated with fouling of the membrane on the support layer. A $1 \%$ sodium hypochlorite $(\mathrm{NaOCl})$ cleaning solution was proved to be effective for removing the foulants from the support layer and recovering the original flux.
\end{abstract}


Keywords: Forward osmosis (FO); Sequential batch reactor (SBR); Fouling, natural organic matter (NOM); Wastewater treatment; Membrane cleaning.

\section{Introduction}

Forward osmosis (FO) is a naturally occurring process driven by the difference of chemical potential of two solutions in contact with the membrane [1]. The high concentration solution is called the draw solution (DS). Water will flow from the low concentration solution (FO feed) to the DS side to achieve solute equilibrium.

The first bench-scale studies of FO for possible application in wastewater treatment were carried out in the early 1970s [2]. FO was also applied to concentrate a sludge dewatering centrifuge containing high concentration of nutrients (e.g. ammonia, phosphate, organic nitrogen) and heavy metals. A meaningful attempt on this process was carried out by using a cellulose triacetate $\mathrm{FO}$ membrane and a $\mathrm{NaCl} \mathrm{DS}$, with high water flux and high nutrient rejection [3].

Sequential batch reactors (SBR) have been widely employed for wastewater treatment. The process consists of filling, aeration, settling, decantation and idling phases in the same reactor. SBR have the ability to achieve high rates of nitrogen, chemical oxygen demand (COD) and phosphate removal [4]. Usually, the operational condition can be classified to be anaerobic, anoxic or oxic (aerobic) processes [5]. The SBR system employs preanoxic denitrification using biochemical oxygen demand (BOD) in the influent wastewater. For many domestic applications, depending on the wastewater strength, sufficient BOD and fill time are available to remove almost all the nitrate remaining in the mixed liquor after the settle and decant steps. Some nitrate removal also occurs during the non-aerated settle and decant periods [6].

A previous study focused on the advantages of an osmotic membrane bioreactor (OsMBR), demonstrating that a sustainable flux can be achieved with relatively low reverse transport of solutes from the DS into the mixed liquor [7]. Membrane fouling was controlled with periodic osmotic backwashing. Other cleaning methods for FO membranes have been reported in literature, including air scouring, osmotic backwash and chemical cleaning [8]. The FO membrane was found to effectively reject nutrients from the wastewater. There are several advantages involved in the use of a SBR compared to a MBR. SBR can provide a higher flow capacity by operating with parallel units; it is also more robust in terms of 
resistance to high levels of BOD or toxic wastewaters [9]. In addition, FO has also been integrated with other processes, such as membrane distillation (MD) and electrodialysis (ED), for wastewater treatment and reuse. The results have been comprehensively reviewed elsewhere [10].

Fouling in the treatment of wastewater by membrane technology usually comprises particles, colloids and organic molecules. If microorganisms are involved, it is usually referred to as biofouling [11]. Biofouling has a significant impact on membrane performance of MBR systems. In a previous study, three stages in formation of biofouling were identified in a MBR system [12]. The presence of extracellular polymeric substances (EPS), comprising polysaccharides, proteins, lipids, and fine colloids, is the first step which leads to pore blocking of new membranes. EPS is produced by the large population of bacteria in suspension and biofilms. In the second stage, the biofilm growth is steady even with a good hydrodynamic environment. Lastly, biofouling will cause flux decline of the FO process.

Physical cleaning methods such as backwashing and membrane relaxation can be applied in MBR [11]. Backwashing can remove most of the reversible fouling causing pore blocking, while membrane relaxation can diffuse away the foulants accumulated near the membrane surface. The membrane productivity will increase significantly if air scouring is applied during relaxation [13]. The effectiveness of physical cleaning methods tends to decrease with time as more irreversible fouling accumulates on the membrane surface. Therefore, chemical cleaning should be applied to the membrane when the flux decline is severe. For organic foulants, the prevalent cleaning agent remains to be sodium hypochlorite, which removes foulants by hydrolyzing the organic molecules and therefore loosening the particles and biofilm attached to the membrane. Lim et al. [14] also studied the effect of sodium hypochlorite on the microbial community of the biofilm in an MBR system, proving that microbial growth was limited in the presence of sodium hypochlorite due to bacterial cell lysis.

To the authors' knowledge, there is few study on the transparent exopolymer particles (TEP) fouling of an FO membrane at the DS side. This is a critical issue when using seawater as DS for FO, TEP might be responsible for biofouling of membranes. Seawater contains significantly larger concentrations of TEP and their precursors (EPS) compared to wastewater effluents, and it was proved that feed water disinfection or microfiltration (MF) are not always effective in removing TEP [15-17]. In addition, hybridization of the FO process and an SBR as primary barriers for the removal of micropollutants and pathogenic microorganisms is novel in the field of wastewater reclamation. 
The main goal of this research was to assess the performance of a hybrid SBR-FO process which treated simulated municipal wastewater and recovered water from the treated effluent through the FO membrane, using seawater as DS. Nutrients removal was investigated. Characterization and cleaning of the FO membrane fouling and biofouling was performed to identify effective techniques to prevent flux decline and maintain the performance of the hybrid SBR-FO system. A diluted seawater from an SBR-FO system can further be treated by low pressure reverse osmosis (LPRO) process defined as indirect desalination [18].

\section{Materials and methods}

\subsection{Sample water}

\subsubsection{Synthetic wastewater}

A synthetic wastewater (SWW) was used to model pre-settled municipal wastewater. The wastewater is a mixture of synthetic wastewater, where the ingredients are based on the expected composition of domestic sewage. The content is based on the average composition and of sanitary wastewater, i.e. the combination of urine and feces. The recipe of the synthetic wastewater is available elsewhere [19]. Concentrations of the chemical oxygen demand (COD), total nitrogen $(\mathrm{N})$ and phosphorus $(\mathrm{P})$ were $439.47 \mathrm{mg} / \mathrm{L}, 60.23 \mathrm{mg} / \mathrm{L}$, and $9.42 \mathrm{mg} / \mathrm{L}$, respectively. The ionic strength of SWW was adjusted by adding a synthetic inorganic solution.

\subsubsection{Pre-filtered seawater}

Red Sea water was used as DS during the FO process. Seawater was obtained from the seawater intake of the KAUST-SWRO plant (located in Thuwal, Saudi Arabia) and prefiltered $(0.45 \mu \mathrm{m}$, glass fiber membrane, GE Whatman, USA) before use. Characterization of DS is given in Table 1. The total suspended solids (TSS) and volatile suspended solids (VSS) of the seawater were 10.3 and $7.1 \mathrm{mg} / \mathrm{L}$, respectively, which suggest the presence of organic particles with a diameter smaller than $0.45 \mu \mathrm{m}$ and possibly colloidal TEP with a size ranging from $0.05 \mu \mathrm{m}$ to $0.4 \mu \mathrm{m}$ [17]. 
Table 1: Characterization of seawater (SW) as the draw solution (DS).

\begin{tabular}{ll}
\hline & $0.45 \mu \mathrm{m}$ pre-filtered seawater \\
\hline Conductivity $(\mu \mathrm{S} / \mathrm{cm})$ & 57500 \\
Temperature $\left({ }^{\circ} \mathrm{C}\right)$ & 20.5 \\
$\mathrm{pH}$ & 7.8 \\
DOC $(\mathrm{mg} / \mathrm{L})$ & 1.15 \\
UVA $254(1 / \mathrm{cm})$ & 0.012 \\
SUVA $(\mathrm{L} / \mathrm{mg} \mathrm{m})$ & 1.07 \\
TDS $(\mathrm{mg} / \mathrm{L})$ & 40500 \\
SDI & 2 \\
Barium $(\mathrm{mg} / \mathrm{L})$ & 0.01 \\
Calcium $(\mathrm{mg} / \mathrm{L})$ & 571 \\
Magnesium $(\mathrm{mg} / \mathrm{L})$ & 1458 \\
Potassium $(\mathrm{mg} / \mathrm{L})$ & 488 \\
Sodium $(\mathrm{mg} / \mathrm{L})$ & 12470 \\
Strontium $(\mathrm{mg} / \mathrm{L})$ & 7 \\
Bicarbonate $(\mathrm{mg} / \mathrm{L})$ & 141 \\
Boron $(\mathrm{mg} / \mathrm{L})$ & 2.2 \\
Carbonate $(\mathrm{mg} / \mathrm{L})$ & 8.0 \\
Chloride $(\mathrm{mg} / \mathrm{L})$ & 23073 \\
Fluoride $(\mathrm{mg} / \mathrm{L})$ & 1.5 \\
Sulphate $(\mathrm{mg} / \mathrm{L})$ & 2400 \\
\hline
\end{tabular}

\subsection{FO membranes and SBR-FO set-up}

A commercial flat-sheet FO membrane was obtained from Hydration Technology Innovations (HTI, Albany, OR, USA). The membrane is made of cellulose triacetate (CTA) embedded in a polyester (PES) screen mesh. The active layer (AL) is the shiny side of the membrane. Before use, the membrane was soaked in deionized (DI) water for $24 \mathrm{~h}$ to remove the glycerin which was used to replace the water during shipment [20]. The FO membrane cell was a custom-made plate and frame assembly made of poly (methyl methacrylate). The membrane cell can hold two flat-sheet membranes each one with an effective area of 200 $\mathrm{cm}^{2}$.

The FO setup has been described elsewhere [21]. Two clean FO membrane coupons were used in the FO flat sheet membrane cell, separated by a diamond-patterned spacer to form the DS recirculation channel. The membrane was tested in two orientations, i.e. active layer (AL) facing the feed water (FO operation mode) and AL facing the DS (PRO mode). A gear pump (Coleparmer) was used to recirculate the DS at a flow rate of $70 \mathrm{~mL} / \mathrm{min}$. A digital balance (TE6101, Sartorius AG, Göttingen, Germany) connected to a computer data logging system monitored the weight variation of DS and converted it to flux. In addition, an online conductivity meter recorded the conductivity decline of the DS over time. A rectangular bubble diffuser (air stone) provided the air need for the aeration periods of the SBR, at a constant air flow rate of $15 \mathrm{~L} / \mathrm{h}$ per liter of wastewater. The temperature of both FO feed and 
DS was maintained at $20 \pm 0.5^{\circ} \mathrm{C}$ by a heater/chiller unit with submerged stainless steel coils. The FO membrane was stabilized with DI water as feed and pre-filtered seawater as DS for 1 day. Fig. 1 shows a detailed scheme of the setup.

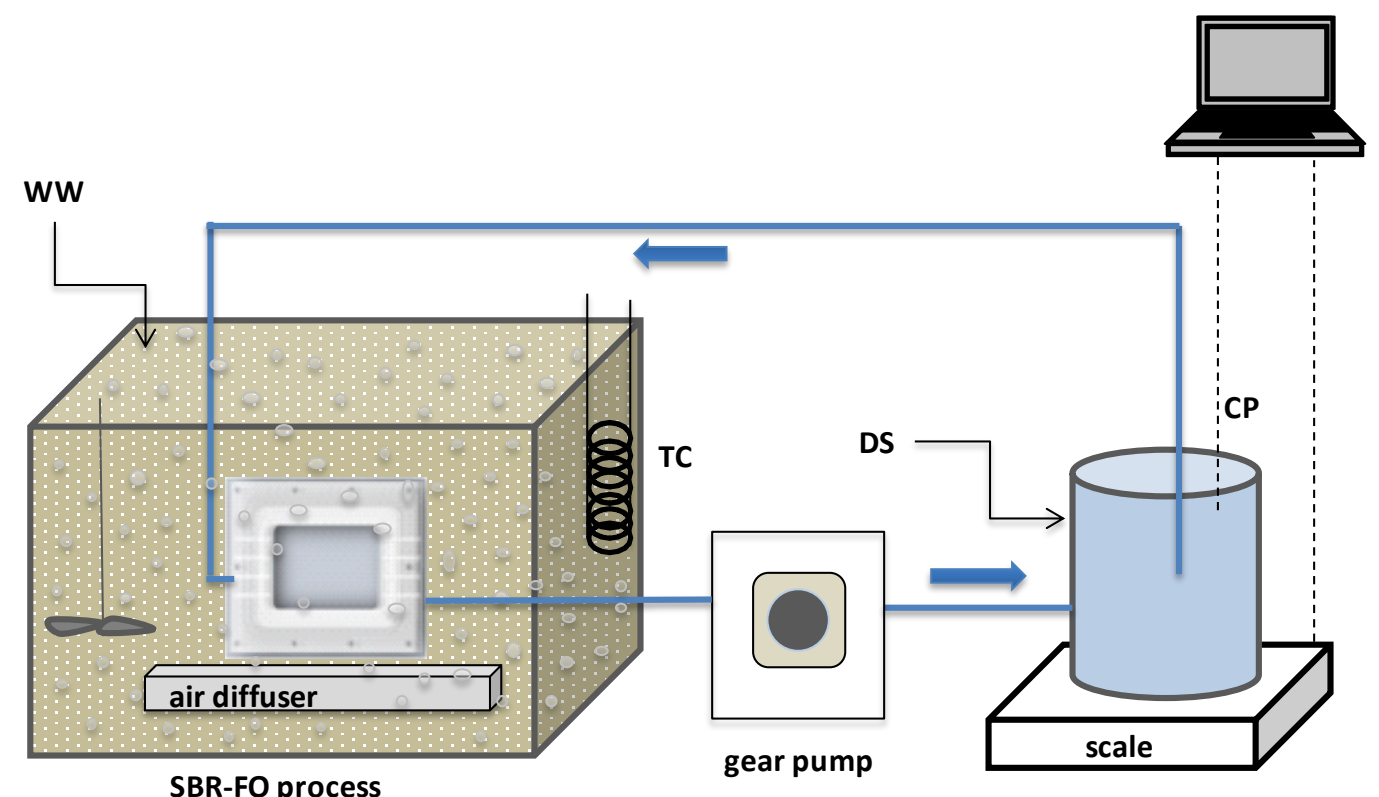

Figure 1: Hybrid sequential batch reactor - forward osmosis (SBR-FO) system layout. CP conductivity probe; DS - draw solution; TC - temperature controller; WW - wastewater.

\subsection{SBR-FO operation phases}

\subsubsection{Start-up phase}

The main purpose of the start-up phase was to produce activated sludge needed for the biological process of the SBR. Real domestic wastewater after primary treatment was collected on KAUST campus. $2 \mathrm{~L}$ of wastewater were mixed with $18 \mathrm{~L}$ of SWW, to inoculate the reactor. After aeration for 2 days, $5 \mathrm{~L}$ of supernatant was removed and replaced by $5 \mathrm{~L}$ of a mixture comprising SWW (4 L) and raw domestic wastewater $(1 \mathrm{~L})$. After repeating the 2day cycle for 3 weeks, the TSS concentration was $606 \mathrm{mg} / \mathrm{L}$ and the VSS concentration was $513 \mathrm{mg} / \mathrm{L}$ in the tank. After the start-up phase the FO cell was immersed into the tank.

\subsection{Stable cycle phase}

After start-up phase, two different cycles were used for the stable phase. Cycle SBR-1 was conducted in three steps: aeration, sedimentation and FO decantation without air scouring. Cycle SBR-2 was conducted in two steps: aeration followed by FO decantation with air scouring. Each cycle was operated for 1 day; the diluted draw solution (DDS) after each cycle 
was replaced by fresh DS. The SBR feed water was adjusted with a mixture of SWW and inorganic solution to keep the conductivity constant. The detailed operational parameters are listed in Table 2.The solids retention time (SRT) was set to 70 days, wasting $5 \mathrm{~L}$ of sludge every two weeks from the $25 \mathrm{~L}$ reactor.

Table 2: Operational parameters during the stable phase of the sequential batch reactor (SBR) for two operation modes: SBR-1 and SBR-2.

\begin{tabular}{lll}
\hline Mode & SBR-1 & SBR-2 \\
\hline Aeration & $6 \mathrm{~h}$ & $8 \mathrm{~h}$ \\
Sedimentation & $2 \mathrm{~h}$ & $0 \mathrm{~h}$ \\
FO decantation & $15 \mathrm{~h}$ no air scouring & $15 \mathrm{~h}$ with air scouring \\
Idle time* & $1 \mathrm{~h}$ & $1 \mathrm{~h}$ \\
Initial draw solution volume & $700 \mathrm{~mL}$ & $300 \mathrm{~mL}$ \\
Feed water conductivity & $2 \mathrm{mS} / \mathrm{cm}$ & $2 \mathrm{mS} / \mathrm{cm}$ \\
TSS of feed water & $<700 \mathrm{mg} / \mathrm{L}$ & $1000 \mathrm{mg} / \mathrm{L}$ \\
\hline
\end{tabular}

* Idle time was used for effluent removal, excess sludge disposal and refilling with the synthetic wastewater.

\subsection{Analytical methods}

\subsubsection{LC-OCD}

A Liquid Chromatograph coupled with Organic Carbon Detection analyser (LC-OCD) (Model 8, DOC LABOR, Germany) was used to analyse the natural organic matter (NOM) [22].

\subsubsection{Adenosine triphosphate (ATP) analysis}

A Celsis Advance Luminometer (Belgium) was used to identify the amount of adenosine triphosphate (ATP) adhered on the FO membrane surface, as well as for those in the DDS and the feed water. The tubes with the samples of the fouling material (diluted in $50 \mathrm{ml}$ ) from the membrane sections with a total area of $9 \mathrm{~cm}^{2}$ were placed in an ultrasonic cleaning bath (Bransonic Model 5510, $40 \mathrm{KHz}$, USA) for 2 minutes, and then mixed on a vortex mixer (Fisher Scientific, $230 \mathrm{~V}$, USA) for 10 seconds at speed 7. This operation was repeated three times. Active biomass was determined in duplicate by measuring the ATP concentration from $50 \mu \mathrm{L}$ samples. The amount of light produced in the reaction was measured with the luminometer (relative light units, RLU). The concentration of ATP was derived from the relative light units value using the conversion factors of the linear relationship between relative light units values and reference ATP concentrations, based on previous work and methods described in literature [23-25]. ATP measurements have been used in previous 
studies to determine accurately the amount of biomass present in a fouling layer on membranes and spacers [24, 26-29].

\subsubsection{TEP identification}

TEP on the membrane surface was observed by Alcian Blue staining (Villacorte et al. 2009) and photographed by microscope (DP72, Olympus, Japan) with bright illumination [17].

\subsubsection{Water analysis kits}

Hach Kits were used to analyze the amount of ammonium (LCK 302 and HACH 69 HR Ammonium), nitrate (LCK 340 and TNT 835), nitrite (LCK 342 and TNT 835), total nitrogen (LCK 238) and phosphate (LCK 350 and TNT 843) in water samples.

\subsection{FO membrane cleaning and flux recovery}

Fouled membrane in the tank was cleaned by different approaches including: air scouring of the AL, chemical cleaning of the AL, osmotic backwash, and chemical cleaning of the SL. The cleaning methods described were used to remove the foulants deposited on the FO membrane. Between each method sufficient cycles were performed to ensure that the flux decline was around $30 \%$ (average flux of $1.99 \mathrm{~L} / \mathrm{m}^{2} . \mathrm{h}$ ) before starting the next cleaning technique. All tests for flux recovery were performed in the SBR 2 cycle and FO mode. The ratio $(\%)$ of average flux of $\mathrm{FO}$ membrane after each cleaning procedure to the average flux measured from new FO membrane was defined as the flux recovery rate.

\subsubsection{Air scouring}

A rectangular bubble diffuser provided the air needed for the air scouring at a constant air flow rate of $15 \mathrm{~L} / \mathrm{h}$ per liter of feed water. Air scouring was applied for 1 hour on each side of the membrane cell.

\subsubsection{Chemical cleaning of the active layer}

The cleaning solution contained $10 \mathrm{~g} / \mathrm{L}$ Alconox (a commercial detergent composed of sodium dodecylbenzenesulfonate (10-30\%), sodium carbonate (7-13\%), tetrasodium pyrophosphate (10-30\%) and sodium phosphate (10-30\%)) and $8 \mathrm{~g} / \mathrm{L}$ sodium ethylenediaminetetraacetic acid (EDTA), with a $\mathrm{pH}$ of 8 to prevent membrane damage. The membrane cell was immersed in the cleaning solution for 20 minutes. After this, the FO cell was washed with DI water and returned to the SBR-FO tank. 


\subsubsection{Osmotic backwash}

The FO cell was immersed in seawater and DI water was circulated inside the cell. The flow rate of DI was kept at $70 \mathrm{~mL} / \mathrm{min}$. After 7 hours of osmotic backwash, the cell was washed with DI water and returned to the SBR-FO tank. A test with DI water as feed water was conducted to evaluate the cleaning effect.

\subsubsection{Chemical cleaning of the support layer}

Two solutions were used respectively to clean the SL of the membrane. The first was $1 \%$ aqueous solution of $\mathrm{NaOCl}(\mathrm{pH}$ 7.6). DI water was used as feed water and $1 \mathrm{~L}$ of $\mathrm{NaOCl}$ solution was recirculated inside the cell at a flow rate of $100 \mathrm{~mL} / \mathrm{min}$ for 25 minutes. The second cleaning solution was the same as that prepared to clean the active layer (i.e. Alconox + sodium EDTA). Again, DI water was used as feed water and $1 \mathrm{~L}$ of cleaning solution was recirculated inside the cell at a flow rate of $100 \mathrm{~mL} / \mathrm{min}$ for 10 minutes. After chemical cleaning, DI water was used to rinse the inside of the cell at a flow rate of $300 \mathrm{~mL} / \mathrm{min}$ for 20 minutes. Then, the cell was washed with DI water and immersed again in the SBR-FO tank.

\section{Results and discussion}

\subsection{FO membrane orientation}

Experiments were done in parallel for new FO membranes in both FO and PRO operation mode. In Fig. 2, the first 7 flux curves on the left were obtained in the FO mode and the 7 curves on the right are results from the PRO mode. Based on the average flux values for the FO process (Table 3), it can be seen that the flux of the PRO mode is higher than the FO mode, due to a reduced internal concentration polarization (ICP) effect in PRO. However, the performance of the FO is more stable than the PRO, the flux in PRO mode rapidly decreases probably due to more sever fouling of the support layer (Fig. 2). Initial fluxes were higher but flux decline is more significant in PRO mode; thus, the FO mode, although with lower initial flux, has been proven to be the most effective in preventing fouling of the FO membrane, obtaining a stable flux along the FO process [30-32]. The average flux in SBR-1 cycle (without air scouring) is lower than the average flux for the SBR-2 cycle (with air scouring) (Table 3). These results might suggest that air scouring applied during the FO decantation in hybrid SBR-FO systems helps to prevent the foulants from accumulating on the membrane surface. These results are consistent with a previous study of OsMBR in crossflow spiral 
wound configuration [33]. Air scouring can enhance the flux due to the bubble-induced water flow which is very important in promoting local mixing to minimize accumulation of solutes and molecules on the membrane [34]. Air scouring also helps to remove and sweep the foulants, due to the cross flow velocity caused, which can generate shear force to break apart the foulant layer. In summary, the FO process showed a better performance than PRO. In addition, FO performance was further improved by air scouring.

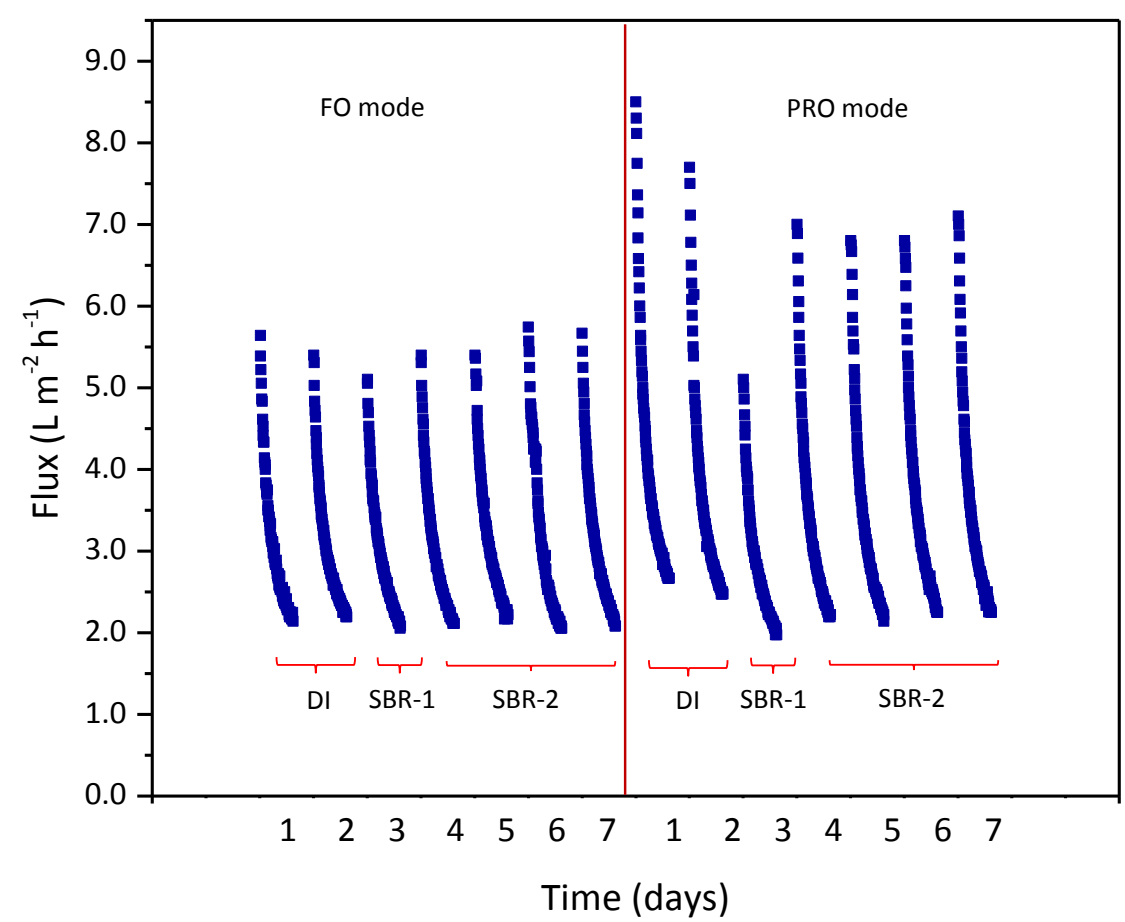

Figure 2: Flux decline for two membrane orientations: active layer facing the feed water (FO mode) and active layer facing the draw side (PRO mode). The first two days, DI water was used as feed water. The next day, the membrane cell was submerged in the SBR and FO was applied after the settling stage without air scouring (SBR-1 cycle). For the last 4 days, the FO process occurred with air scouring immediately after the aeration stage (SBR-2 cycle).

Table 3: Average fluxes for FO process in different membrane orientations and SBR modes.

\begin{tabular}{lll}
\hline & $\begin{array}{l}\text { Average flux FO mode } \\
\left(\mathrm{L} / \mathrm{m}^{2} . \mathrm{h}\right)\end{array}$ & $\begin{array}{l}\text { Average PRO mode } \\
\left(\mathrm{L} / \mathrm{m}^{2} . \mathrm{h}\right)\end{array}$ \\
\hline DI water & 3.06 & 3.88 \\
SBR-1 & 2.95 & 2.85 \\
SBR-2 & 3.10 & 3.47 \\
\hline
\end{tabular}




\subsection{Fouling of the active layer of FO membrane}

For the rest of the experiments, SBR-2 cycle was used with the membrane oriented in the FO mode.

After 3 months of continuous operation of the SBR-FO system, an analysis of the fouling on the membrane and water quality parameters was performed. Fig. 3 shows the results for the LC-OCD analysis of the DS (seawater), the DDS 1, which corresponds to the diluted draw solution that comes from the process that used a FO membrane for 3 months in the SBR-FO system, and DDS 2, which was produced with a new FO membrane. Both samples had lower biopolymer concentrations than seawater since this fraction is not partitioning to the DS. Reduction in concentration of humics and building blocks in both samples was also observed. Although a reduction of low molecular weight (LMW) acids was observed in both cases, when using the new membrane, the reduction was less than that for the 3-month used membrane, possibly due to membrane blocking, which reduces the size of the pores and prevents LMW substances from partitioning to the DS. Nevertheless, as the molecular weight decreases, the FO membrane is not able to reject these compounds and they will be transported to the DS side, as seen with the LMW neutrals, such as urea [35]. The increase in concentration for this fraction was considerably higher when the membrane has been used for 3 months. This is attributed to cumulative concentration of this fraction (e.g. urea from SWW) by adding SWW to adjust feed after each cycle. In addition, biological degradation and hydrolysis of the NOM bigger fractions (i.e. biopolymers, humics) during a long-term operation could also increase the amount of LMW neutrals which can pass through the FO membrane used in this study [35]. 


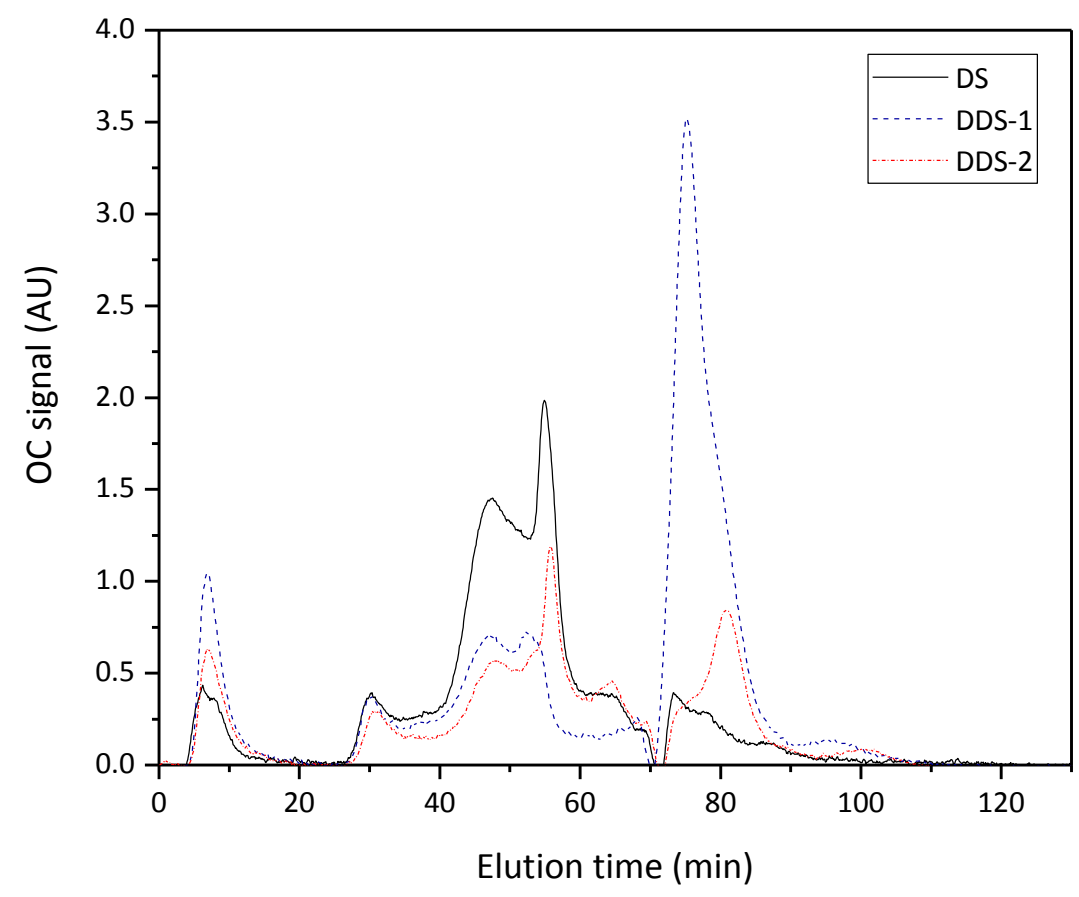

Figure 3: LC-OCD chromatograms for draw solution (DS) and diluted draw solution 1 and 2 draw solution 2 (DDS-1 and DDS-2).

Table 4 shows the results of ATP concentrations found in the samples of the fouling layer and the DDS. An analysis of a fouled FO membrane immersed in a secondary wastewater effluent (SWWE) was also included in the results as a comparison. The fouling layer in both cases contained alive and active microorganisms, indicating that the membranes were affected by biofouling. In addition, when compared to the fouled FO membrane with SWWE as feed, the SBR-FO system shows a 40 times higher biomass concentration, reaching almost $50 \times 10^{3}$ $\mathrm{pg} \mathrm{ATP} / \mathrm{cm}^{2}$. The results suggest that biofouling might be a problem during long term operations in FO. Concentration of ATP in the DDS sample was negligible. The FO membrane proved to be a good barrier against microorganisms.

Table 4: Adenosine triphosphate (ATP, active biomass) measurements for the FO membrane and the diluted draw solution (DDS) after a runtime of 3 months.

\begin{tabular}{lll}
\hline Sample & unit & value $^{-}$ \\
\hline FO fouled membrane in FO* & pg ATP cm & $12 \times 10^{3}$ \\
FO fouled membrane in SBR-FO & pg ATP cm & $49 \times 10^{3}$ \\
DDS & ATP $(\mu \mathrm{g} / \mathrm{L})$ & $<0.1$ \\
\hline *Using a secondary wastewater effluent as feed water, seawater as DS
\end{tabular}




\subsection{Fouling of the support layer of FO membrane}

After 3 months of operation with the SBR-FO system, the membrane was analysed to determine the presence of TEP in both active and support layer of the FO membrane. Fig. 4 shows images of both layers of the membrane. TEP clusters can be identified in the FO membrane support layer as blue stains (Alcian Blue dye), which has been reported in the literature previously [36]. These particles originated from the seawater (DS), as this test was conducted with the support layer facing the DS [17]. On the other hand, the image of the active layer does not show any TEP accumulation, which suggests that the feed water does not contain a significant amount of these particles.
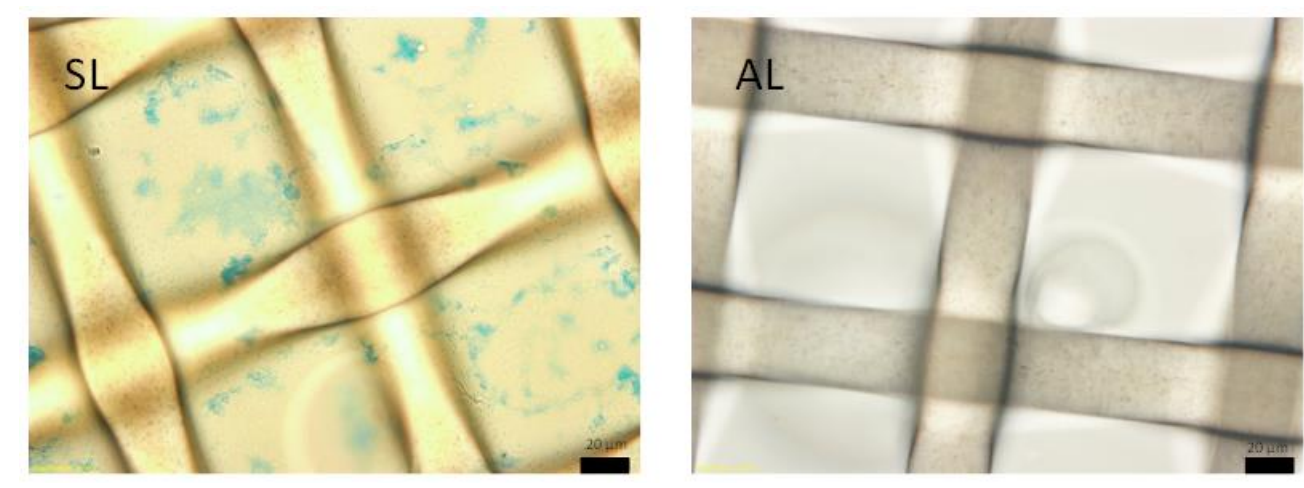

Figure 4: Support layer (SL) and the active layer (AL) of a FO membrane after 2 months of operation in SBR-FO system. For the SL, blue clusters show transparent exopolymeric particle (TEP) fouling, not present in the AL.

\subsection{Cleaning of the FO membrane}

\subsubsection{Active layer cleaning}

All tests for flux recovery were performed in the SBR 2 cycle and FO mode, and the average flux considered for the clean membrane was established as $2.86 \mathrm{~L} / \mathrm{m}^{2} . \mathrm{h}$ (Fig. 5 and Fig. 6).

In osmotic backwash (Figs. 5(c) and 6(c)), water passed through the FO membrane from inside the FO cell to the outside (from the support layer to active layer). The objective was to change the water flow direction by exchanging the salt concentration gradient over the membrane, promoting the removal of accumulated foulants on the active layer. A part of these foulants was washed away by the water flux; however, it might not be sufficient to remove the attached NOM particles nor biofouling. On the other hand, this reversed flow might enhance the attachment of TEP foulants on the support side of the membrane, decreasing the efficiency of the active layer cleaning. 
The second method used was air scouring of the FO membrane. The cell was submerged into DI water for 1 hour to remove foulants. Afterwards, the SBR-FO system was tested again and the results are shown on Figs. 5(d) and 6 (d). Flux recovery was 89.5\%, with an average flux of $2.56 \mathrm{~L} / \mathrm{m}^{2}$.h. Air bubbles significantly removed particles attached to the membrane surface. The last method used to clean the active layer of the fouled membrane was chemical cleaning with a solution of Alconox and sodium EDTA (described in section 2.5.2). The flux recovered was $84.3 \%$ (average flux of $2.41 \mathrm{~L} / \mathrm{m}^{2}$.h) (Figs. 5(e) and 6(e)). The result suggested that the performance of detergents used for chemical cleaning is not as effective as air scouring in this study. The optimal detergent should be identified in future study for removing fouling caused by municipal wastewater and seawater on FO membrane.

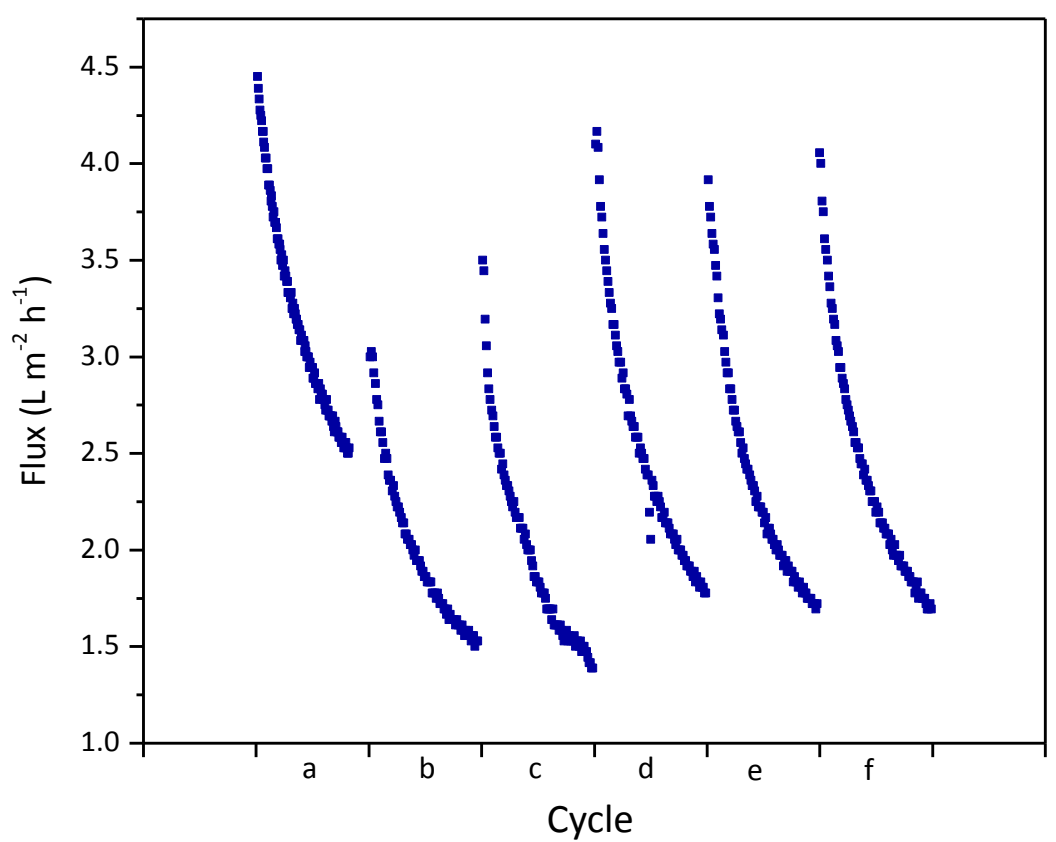

Figure 5: Flux recovery of different cleaning methods. (a) Flux of a new FO membrane in SBR-FO system. (b) $30 \%$ flux decline curve. (c) Flux recovery after osmotic backwash. (d) Flux recovery after air scouring with DI water as feed on the active layer for 1 hour. (e) Flux recovery after chemical cleaning of the active layer (Alconox + sodium EDTA). (f) Flux recovery after chemical cleaning of the support layer with $1 \% \mathrm{NaOCl}$. 


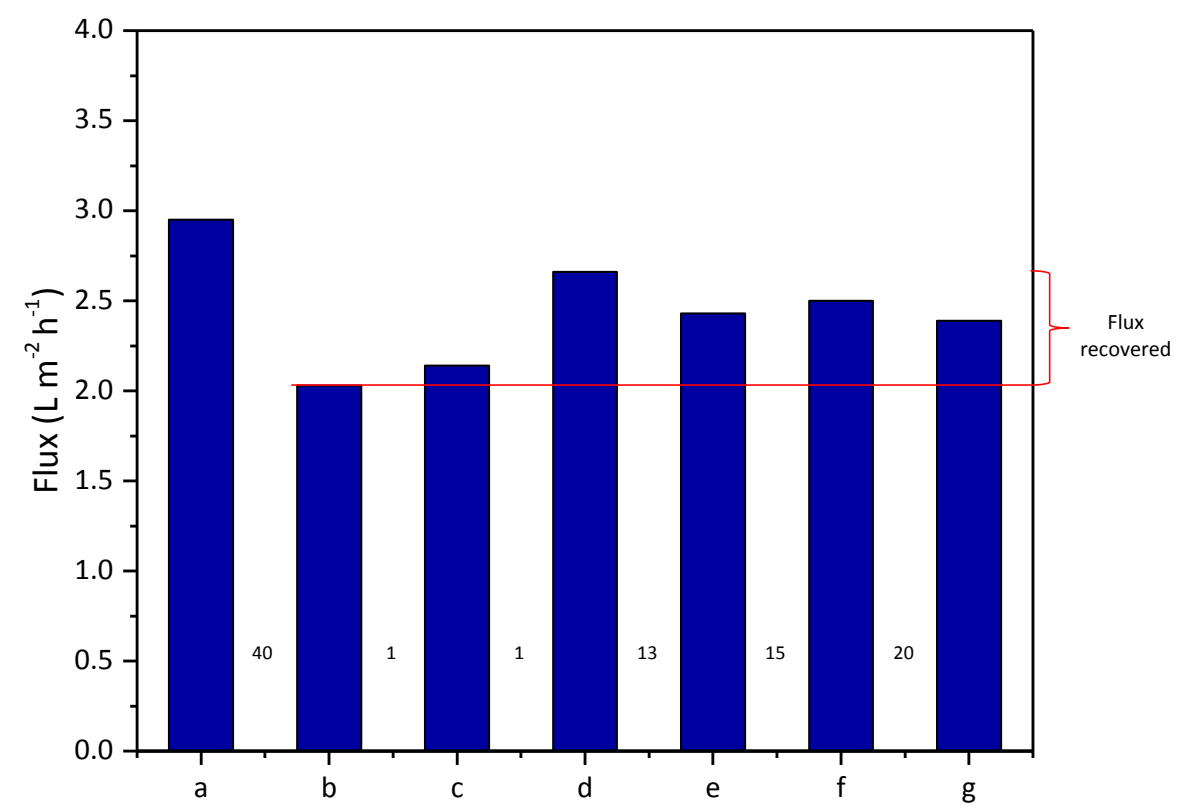

Figure 6: Average FO flux after the different cleaning techniques and days in between. (a) New FO membrane in SBR-FO system; (b) 30\% flux decline curve; (c) osmotic backwash; (d) air scouring; (e) chemical cleaning of the active layer (Alconox + sodium EDTA). (f) chemical cleaning of the support layer $(1 \% \mathrm{NaOCl})$; $(\mathrm{g})$ chemical cleaning of the support layer (Alconox + EDTA).

\subsubsection{Chemical cleaning of the support layer}

Two types of cleaning reagents were employed to clean the support layer of the FO membrane. $1 \mathrm{~L}$ of $1 \% \mathrm{NaOCl}$ solution was used as DS and DI water was used as the feed water to clean. After 25 minutes of cleaning, the membrane was tested and the average flux was $2.46 \mathrm{~L} / \mathrm{m}^{2}$.h; the flux recovery was $86 \%$ (Figs. 5(f) and 6(f)).

Chemical cleaning of the membrane was also performed with a solution of Alconox and sodium EDTA, used as DS; DI water was used as feed water (Fig. 6(g)). The membrane had a flux of $2.36 \mathrm{~L} / \mathrm{m}^{2}$.h after cleaning. Successful TEP removal from FO membrane surface has been reported when using a solution of Alconox and sodium EDTA [8]. Fig. 6 shows that the most effective cleaning method for the active layer under the experimental conditions of this study is air scouring, and for the support layer, chemical cleaning with $1 \% \mathrm{NaOCl}$ solution, achieving both a flux recovery higher than $85 \%$ of the flux of a clean membrane after a flux decline of $30 \%$. 


\subsection{DOC and nutrients removal}

\subsubsection{DOC removal efficiency}

Considering the SBR alone (the microbial process without FO decantation), wastewater feed was considered as the inlet water and the SBR effluent (SBRE) was the outlet water. Therefore the removal efficiency of SBR alone can be calculated with Eq. (1):

$$
\mathrm{DOC}_{\text {removal efficiency }}=\left(\left(\mathrm{DOC} \mathrm{WW}_{\mathrm{W}}-\mathrm{DOC}_{\mathrm{SBRE}}\right) / \mathrm{DOC} \mathrm{WW}_{\mathrm{W}}\right) \times 100 \%
$$

DOC of the WW and SBRE were $80.22 \mathrm{mg} / \mathrm{L}$ and $3.32 \mathrm{mg} / \mathrm{L}$, respectively. The DOC removal efficiency of the SBR process was $95.86 \%$, which is an acceptable removal efficiency for a conventional SBR.

For the hybrid SBR-FO process, the WW was considered as the inlet water and DDS was considered as the effluent. The DOC removal efficiency of the hybrid system process can be calculated by Equation 2 taking into consideration that the concentration of DOC in the DDS is equal to the concentration of DOC in the water permeating through the membrane:

$$
\mathrm{DOC}_{\text {removal efficiency }}=\left(\left(\mathrm{DOC} \mathrm{WW}_{\mathrm{W}}-\mathrm{DOC}_{\mathrm{DDS}}\right) / \mathrm{DOC} \mathrm{WW}\right) \times 100 \%
$$

DOC of DDS was $1.15 \mathrm{mg} / \mathrm{L}$. Therefore the DOC removal efficiency of the hybrid SBR-FO system was $98.55 \%$.

\subsubsection{Nutrients removal}

Nutrients removed from feed water by SBR-FO are shown in Fig. 7. The lowest removal efficiency was identified for nitrate (58.4\%). It might be associated with the size of the particles, and most importantly, to the almost continuous aeration in the SBR system, which promoted oxidation of nitrogen species into nitrate. This phenomenon is also responsible for the low concentration of nitrite found in the feed water, and thus, the low concentration and high removal efficiency of this specie with the SBR-FO system (96.2\%). Similarly, although the ammonium has a low molecular weight, it is the reduced specie of nitrogen. This makes it vulnerable of being transformed into nitrite and nitrate with the oxygen available in the reactor; removal of ammonium was $88.4 \%$. Total nitrogen removal was $62.4 \%$. Phosphate had the highest removal efficiency, which was about $100 \%$. It is possible that this is due to 
the relation with the FO membrane surface negative charge, the high negative charge of the particle and its size, being bigger than nitrate, nitrite and ammonium.

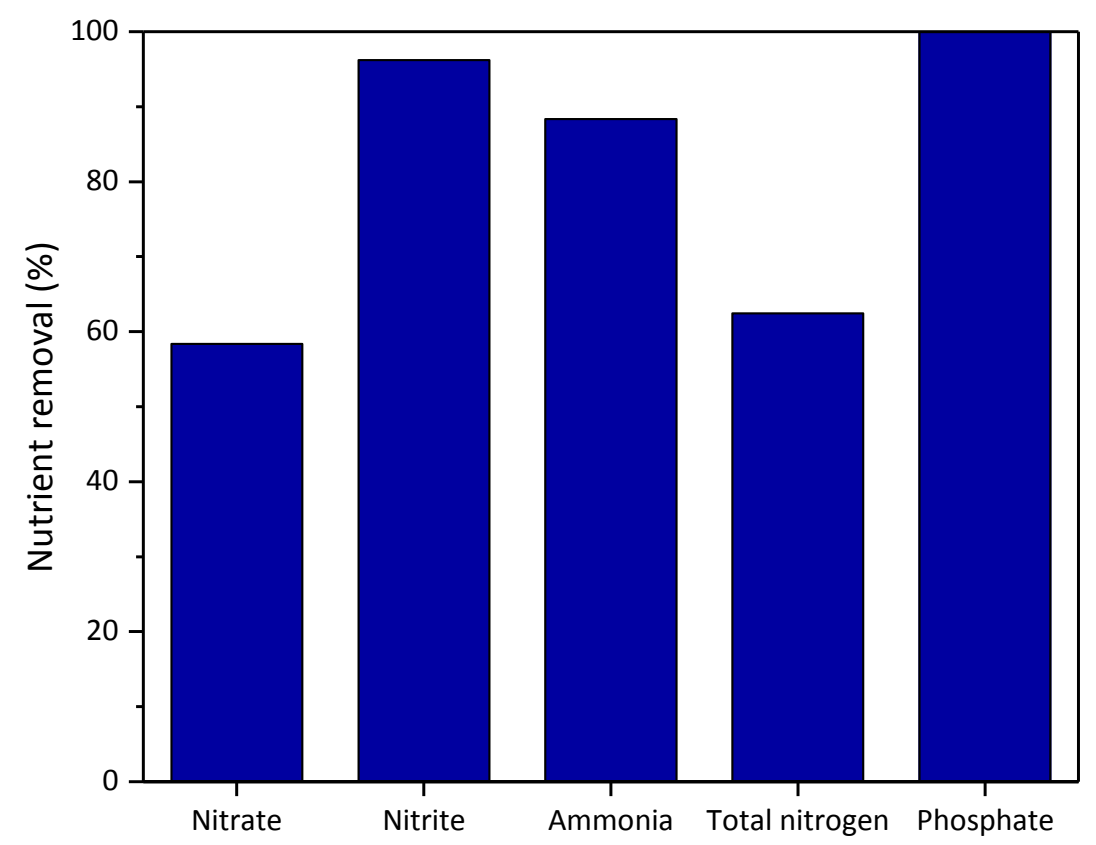

Figure 7: Nutrients removal (\%) for the hybrid SBR-FO system.

A life cycle cost assessment has determined the advantages of large scale industrial hybrid FO systems for seawater desalination and wastewater recovery and reuse. Based on development on FO membrane modules, packing density, and water permeability, the total water cost could be further reduced [37].

\section{Conclusions}

1) FO membrane orientation has a significant impact on the membrane flux and fouling in a SBR-FO configuration. When the active layer faces the feed (FO mode), the flux performance is more stable than for PRO mode, because when the active layer is in contact with the wastewater feed, fouling is significantly decreased in FO.

2) LC-OCD and 3-D FEEM images showed that the FO membrane in an SBR-FO system has a very good performance in rejecting high molecular weight compounds like biopolymers, humics and building blocks, but it has a limited ability in rejecting low molecular weight neutrals. Biofouling of the FO membrane is considerable and might impact the long-term system performance.

3) Air scouring in SBR-FO systems can help recover the flux up to $89.5 \%$. In this study, air scouring is more effective than osmotic backwash and chemical cleaning of the active layer. 
The favorable detergents for chemical cleaning of FO membrane fouled by municipal wastewater should be identified in future study. TEP attached to the support layer of the FO membrane can be cleaned resulting in a good flux recovery $(86 \%)$ with a $1 \% \mathrm{NaOCl}$ solution.

4) It is feasible to treat synthetic municipal wastewater by the proposed hybrid SBR-FO system. DOC removal recovery is $98.55 \%$. The total nitrogen removal is $62.4 \%$ during FO decantation with air scouring.

\section{Acknowledgements}

The research reported in this paper was supported by King Abdullah University of Science and Technology (KAUST), Saudi Arabia. The authors would like to thank Hydration Technology Innovations for providing the FO membranes. Authors extend their gratitude to the Water Desalination and Reuse Center (WDRC) staff for the support.

\section{References}

[1] T.Y. Cath, N. T. Hancock, C. D. Lundin, C. Hoppe-Jones, and J. r. E. Drewes. A multibarrier osmotic dilution process for simultaneous desalination and purification of impaired water. Journal of Membrane Science 362 (2010) 417-426.

[2] F. Votta, S. M. Barnett, and D. K. Anderson. Concentration of industrial waste by direct osmosis. Providence, RI. 1974.

[3] R.W. Holloway, A. E. Childress, K. E. Dennett, and T. Y. Cath. Forward osmosis for concentration of anaerobic digester centrate. water research 41(2007) 4005-4014.

[4] S. Zou, Y. Gu, D. Xiao, and C. Y. Tang. The role of physical and chemical parameters on forward osmosis membrane fouling during algae separation. Journal of Membrane Science 366 (2011) 356-362.

[5] Metcalf and Eddy. Wastewater Engineering Treatment and Reuse. 4th Edition edition. McGraw Hill. 2003.

[6] G. Tchobanoglous, F. L. Burton, and H. D. Stensel. Wastewater engineering: treatment and reuse. McGraw Hill, NY. 2003.

[7] A. Achilli, T. Y. Cath, E. A. Marchand, and A. E. Childress. The forward osmosis membrane bioreactor: A low fouling alternative to MBR processes. Desalination 239 (2009) 10-21. 
[8] R. Valladares Linares, Z.Y. Li, V. Yangali-Quintanilla, Q. Li, and G. Amy. Cleaning protocol for a FO membrane fouled in wastewater reuse. Desalination and Water Treatment 51 (2013) 25-27. [9] P.V. Bhaskar, H.-P. Grossart, N. B. Bhosle, and M. Simon. Production of macroaggregates from dissolved exopolymeric substances (EPS) of bacterial and diatom origin. FEMS Microbiology Ecology 53 (2005) 255-264.

[10] R. Valladares Linares, Z.Y. Li, S. Sarp, Sz.S. Bucs, and G. Amy, and J.S. Vrouwenvelder. Forward osmosis niches in seawater desalination and wastewater reuse. Water Research 66 (2014) 122-139.

[11] P. Le-Clech, V. Chen, and T. A. G. Fane. Fouling in membrane bioreactors used in wastewater treatment. Journal of Membrane Science 284 (2006) 17-53.

[12] H.M. Zhang, J.N. Xiao, Y.J. Cheng, L.F. Liu, X.W. Zhang, and F.L. Yang. Comparison between a sequencing batch membrane bioreactor and a conventional membrane bioreactor. Process Biochemistry 41 (2006) 87-95.

[13] H.C. Chua, T. C. Arnot, and J. A. Howell. Controlling fouling in membrane bioreactors operated with a variable throughput. Desalination 149 (2002) 225-229.

[14] B.R. Lim, K. H. Ahn, K. G. Song, and J. W. Cho. Microbial community in biofilm on membrane surface of submerged MBR: effect of in-line cleaning chemical agent. Water Science \& Technology 51 (2005) 201-207.

[15] K.Y. Wang, T.S. Chung, and J.J. Qin. Polybenzimidazole (PBI) nanofiltration hollow fiber membranes applied in forward osmosis process. Journal of Membrane Science 300 (2007) 6-12.

[16] E. Bar-Zeev, I. Berman-Frank, B. Liberman, E. Rahav, U. Passow, and T. Berman. Transparent exopolymer particles: Potential agents for organic fouling and biofilm formation in desalination and water treatment plants. Desalination and Water Treatment 3 (2009) 136-142.

[17] L.O. Villacorte, M. D. Kennedy, G. L. Amy, and J. C. Schippers. The fate of Transparent Exopolymer Particles (TEP) in integrated membrane systems: Removal through pretreatment processes and deposition on reverse osmosis membranes. Water Research 43 (2009) 5039-5052.

[18] V. Yangali-Quintanilla, Z. Li, R. Valladares, Q. Li, and G. Amy. Indirect desalination of Red Sea water with forward osmosis and low pressure reverse osmosis for water reuse. Desalination 280 (2011) 160-166.

[19] I. Nopens, C. Capalozza, and P. A. Vanrolleghem. Stability analysis of a synthetic municipal wastewater. Universiteit Gent, Gent. 2001. 
[20] Z. Li, V. Yangali-Quintanilla, R. Valladares Linares, Q. Li, T. Zhan and G. Amy. Flux patterns and membrane fouling propensity during desalination of seawater by forward osmosis. Water Research 46 (2012) 195-204.

[21] R. Valladares Linares, V. Yangali-Quintanilla, Z. Li, and G. Amy. Rejection of micropollutants by clean and fouled forward osmosis membrane. Water Research 45 (2011) 6737-6744.

[22] S.A. Huber, A. Balz, M. Abert, and W. Pronk. Characterisation of aquatic humic and nonhumic matter with size-exclusion chromatography - organic carbon detection - organic nitrogen detection (LC-OCD-OND). Water Research 45 (2011) 879-885.

[23] O. Holm-Hansen and C.R. Booth. Measurement of adenosine triphosphate in the ocean and its ecological significance. Limnology and Oceanography 11 (1966) 510-519.

[24] J.S. Vrouwenvelder, Manolarakis, S.A., van der Hoek, J.P., van Paassen, J.A.M., van der Meer, W.G.J., van Agtmaal, J.M.C., Prummel, H.D.M., Kruithof, J.C., van Loosdrecht, M.C.M. Quantitative biofouling diagnosis in full scale nanofiltration and reverse osmosis installations. Water Research 42 (2008) 4856-4868.

[25] D.M. Karl. Cellular nucleotide measurements and applications in microbial ecology. Microbiol. Rev., 44(4) (1980) 739-796.

[26] D. Van der Kooij, J.S. Vrouwenvelder, and H.R. Veenendaal. Elucidation and control of biofilm formation processes in water treatment and distribution using the unified biofilm approach. Water Science \& Technology 47 (5) (2003) 83-90.

[27] D.J. Miller, P.A. Araújo, P.B. Correia, M.M. Ramsey, J.C. Kruithof, M.C.M. van Loosdrecht, B.D. Freeman, D.R. Paul, M. Whiteley, and J.S. Vrouwenvelder. Short-term adhesion and long-term biofouling testing of polydopamine and poly(ethylene glycol) surface modifications of membranes and feed spacers. Water Research 46 (2012) 37373753.

[28] A. Siddiqui, N. Farhat, S. S. Bucs, R. Valladares Linares, C. Picioreanu, J.C.Kruithof, M.C.M. van Loosdrecht, J. Kidwell, and J.S. Vrouwenvelder. Development and characterization of 3D-printed feed spacers for spiral wound membrane systems. Water Research 91 (2016) 55-67.

[29] R. Valladares Linares, S.S. Bucs, Z. Li, M. Abu-Ghdeeb, G. Amy, and J.S. Vrouwenvelder. Impact of spacer thickness on biofouling in forward osmosis. Water Research 57 (2014) 223-233. 
[30] E.R. Cornelissen, D. Harmsen, K. F. de Korte, C. J. Ruiken, J.-J. Qin, H. Oo, and L. P. Wessels. Membrane fouling and process performance of forward osmosis membranes on activated sludge. Journal of Membrane Science 319 (2008) 158-168.

[31] B. Mi, and M. Elimelech. Chemical and physical aspects of organic fouling of forward osmosis membranes. Journal of Membrane Science 320 (2008) 292-302.

[32] Y. Wang, F. Wicaksana, C. Y. Tang, and A. G. Fane. Direct Microscopic Observation of Forward Osmosis Membrane Fouling. Environmental Science \& Technology 44 (2010) 7102-7109.

[33] J.J. Qin, K. A. Kekre, M. H. Oo, G. Tao, C. L. Lay, C. H. Lew, E. R. Cornelissen, and C. J. Ruiken. Preliminary study of osmotic membrane bioreactor: effects of draw solution on water flux and air scouring on fouling. Water Science and Technology 62 (2010) 13531360.

[34] Z.Y. Li, A. H-Kittikun, and W. Youravong. Separation of protease from yellowfin tuna spleen extract by ultrafiltration: Effect of hydrodynamics and gas sparging on flux enhancement and selectivity. Journal of Membrane Science 311 (2008) 104-111.

[35] R. Valladares Linares, Z. Li, M. Abu-Ghdeeb, C.H. Wei, G. Amy, and J.S. Vrouwenvelder. Water harvesting from municipal wastewater via osmotic gradient: an evaluation of process performance. Journal of Membrane Science 447 (2013) 50-56.

[36] T. Berman and R. Parparova. Visualization of transparent exopolymer particles (TEP) in various source waters. Desalination and Water Treatment 21 (2010) 382-389.

[37] R. Valladares Linares, Z. Li, V. Yangali-Quintanilla, N. Ghaffour, G. Amy, T. Leiknes, and J. S. Vrouwenvelder. Life cycle cost of a hybrid forward osmosis - low pressure reverse osmosis system for seawater desalination and wastewater recovery. Water Research 88 (2016) 225-234. 